\title{
Green Garment Design based on Sustainable Background
}

\section{Zhexin LIU}

Zhuhai College of Jilin University, Zhuhai, China

Bing HAN

Zhuhai nanping middle school, Zhuhai, China

Zheli LIU

Nankai University, Nankai, China

\begin{abstract}
The green garment design under the guidance of sustainable development, clothing design must proceed from the requirements of protect environment, through the design to create a no pollution and ecological environment favorable to the sustainable development of human society, makes the harmonious coexistence between human and environment. Garment design under the concept of green design should achieve sustainable development, so we must fully consider its design style, fabric selection, function design and characteristics of the other aspects, to simplify the fabric style, ecological, functional diversity.
\end{abstract} KEYWORD: sustainable development; green design; garment design

\section{INTRODUCTION}

Sustainable development and environmental problems have become a global issue, in the field of garment design adhere to the green design application of sustainable concept has become more and more important. On the garment design, under the leading of sustainable development and green design, people-oriented design principles have been generally recognized by the people. At present, an important development direction of clothing design is how to through the green design innovation to promote sustainable garment design.

Green design (GD) is also called ecological design (ED), It is in the product life cycle, consider a design focused on the environmental attributes of products that are designed to meet the environmental objectives and requirements, while ensuring functional product applications. Green Design for the product's entire life cycle, throughout the life cycle of products green degree regarded as a design goal.

\section{GREEN CHOICE OF FABRIC}

Green fashion design products should first be required to construct materials with green properties, In other words, the entire life cycle of clothing, such materials should be conducive to reducing energy consumption, environmental burden lightest, specifically, it should meet the following requirements:

\subsection{Clothing material should be used for low-power, low-cost and low-polluting materials.}

This is from the production process of the material itself used to consider. In other words, the manufacturing process of green design clothing material is also proposed strict requirements: Green garment design, protection of the environment should choose low-power, low-cost, less pollution clothing materials.

\subsection{Clothing material should be used for ease of processing and processing pollution or contamination is minimized.}

This is a process from material manufacture clothing to consider. In-depth analysis from the fiber manufacturing, textile manufacturing to garment production process, select the ease of processing and processing of non-polluting or less polluting materials are required to reduce green clothing assurance, control of the production process to ensure that contamination. In other words, clothing materials should be chosen so that the manufacturing process produces minimal waste, and minimize environmental pollution.

\subsection{Clothing materials used should be easy to recycle, easy to handle, reusable, biodegradable materials.}

It is easy to handle from the perspective of clothing to be considered abandoned. Choose easy recovery, 
easy processing materials, prevent the earth mineral resource depletion, and effectively protect environment. In green garment design, material selection should follow the following two principles: One is the use of recycled materials in nature as much as possible, and will be applied to the natural circulation waste and production process; The second is to use as little as possible the nature of non-recyclable materials, and non-use of those materials cannot, and should advance the design of a recycling system in the process of waste and recycled material, strictly control the number, and it is in an inactive state.

Winter clothes such as China famous brand "Bo sideng" and "snow flying" down jacket lining fabric on the selection of a new type of environmentally friendly materialsTyvek in collaboration with DuPont production company. It is lightweight, durable, wind resistant and breathable, It solves the heat cannot be dissipated as a result of which led down damp, moldy, puzzle bonded into a group, and make a down jacket feel softer and more comfortable to wear, you can quickly degrade under certain conditions, can also do other useful after recycling. This selection of fabrics for garment design, with practical and applicable functions show concept of sustainable development and green design.

With the development of science and technology, the new eco-friendly fabric endless, for the sustainable development of fashion design industry offers a variety of possible, but also for the designer of green design offers a variety of new materials, these new raw material in the production, processing, use, recycling and other process does not produce pollution and help protect the environment, harmless or beneficial to human health. Such as soy fiber, milk fiber, bamboo fiber, Tencel, pineapple fibers, organic cotton, pearl fiber, chitin fiber, have biodegradable, does not pose a problem on the environment, and moisture permeability, good strength, anti-static, conducive to human health.

\section{STRUCTURE PROCESS DESIGN}

\subsection{Costume design for disassembly}

In garment design, it is usually considered more clothing each component connectivity, but rarely consider the demolition of clothing, however, waste clothing components may be reused, and then these components must be able to be easily remove, disassembly is a prerequisite for product recycling, the direct impact of recyclable products, design ideas and methods for the demolition of clothing also emerged.

Removal of clothing from the clothing is removed regularly available process components, while ensuring no damage due to the demolition process and the component. Clothing demolished two purposes: First, to reuse parts of clothing, the second is recycled clothing materials.

Disassembly design is an earlier and more systematic method of green design research, and has been used in automobiles, computers, copiers and other products. Although some fashion designers have tried to disassemble design as a new concept into the costume designs, but in the actual demolition applications designed garment production is still very small, with the promotion of green design clothing, disassembly design will get widespread attention, and will gradually establish a clothing design criteria and disassembly evaluation system.

\subsection{Design for recycling}

Costume design is recovered in product design, fully consider the possibility of clothing recycling parts and materials, the size of the recovery value, recycling methods, recycling and other recyclable construction craft a series of issues related to, in order to achieve full and effective use of resources and energy components and materials, and in the recovery process of the environmental pollution to a minimum of a design idea and method.

Recycling here is a broad recovery, recycling design clothing that is not only considered the most basic material recovery, more concerned with the components and materials in new products utilizing used or waste products. Collection and recycling of product forms are varied, for the same product can have multiple forms of recycling. The two main factors to be considered in the design of the disposal are the cost of disassembly and recycling of waste products of problem. Because recycling and product reconstruction techniques are evolving, it increases the hardness of utilizing waste products, and to solve this difficult problem can be the following two basic criteria: First remove the waste products in the most valuable part; to maximize the production efficiency of each detaching works. But one thing we must be clear that, for a product in order to achieve one hundred percent completely recyclable is impossible and not economical, so some demolition recycling is the most economical way.

\section{PACKAGING DESIGN OF GREEN CLOTHING PRODUCTS}

Green garment products must be green packaging, so that it has the overall image of green products and competitive advantage. Green packaging design typically includes packaging solutions and structure, the choice is easy to handle, biodegradable, recyclable or recycled packaging materials. On the one hand clothing products with green products 
overall image and market competitive advantage, at the same time, does not pollute the environment when ithave abandoned. Used clothing boxes, bags with biodegradable paper and PVA, recyclable polypropylene film are better. Use green marketing methods to promote public green consumption, to build a green consumer market, and promote sustainable economic development.

\section{ESTABLISH AND RICH GREEN CLOTHING PRODUCTS DATABASE AND KNOWLEDGE BASE}

Continue to accumulate relevant data and knowledge of all product lifecycle and environmental, economic, technological, countermeasures. Such as clothing material's impact of the environment values, material degradation cycle, artificial degradation cycle and methods, in the clothing manufacture, sale and use of the waste generated during the environmental impact of value, as well as a variety of criteria and design experience about green garment products.

\section{PRESENT AND PROSPECT OF GREEN CLOTHING DESIGN}

Faced with the challenge of WTO, the environmental problems in Chinese garment industry has become a key factor restricting China's garment industry competitiveness. To this end, sustainable green costume design development and research has been referred to the research agenda. Domestic green garment products compared to developed countries and the world, whether there is a big gap in the variety and quantity. The main reason: First, the domestic garment green consumer has not yet formed, leading to the market as the core of the enterprise ecosystem weak awareness; second, the lack of systematic green design theory and design principles.

Harmonious relationship between man and nature is considered to be a severe test of the 21 st century. Green garment fashion as a new concept was promptly put out. It includes green and sustainability advocate wearing apparel fabrics and fashion accessories. Introduce the idea of sustainable development of garment design, advocate the consumption and use of green design clothing, wearing apparel extend the timeliness, will become an important selling point for the future of the garment market.
At present, the international community has developed eco- clothing listed with deodorant, antibacterial, anti-inflammatory, anti-ultraviolet radiation, eliminate itching, heat resistance, and promote a variety of functions, such as human microcirculation. Although many products are still in its infancy, but the ecological clothing design and consumption will become the mainstream market. With the domestic and international markets increasing emphasis on eco-products, green products will become the future development direction of the garment industry.

\section{CONCLUSION}

Green garment design for sustainable development, we must fully consider the characteristics of the various aspects of its design, fabric selection, functional design and production, marketing, etc., consider product recycling after use and recycling, reducing waste generation at the source, to extend the product life cycle, on the basis of protecting the environment becomes more balanced ecosystems, and ultimately promote the sustainable development of human society through design activities to humans and the environment can coexist in harmony.

\section{ACKNOWLEDGEMENTS}

This work is supported by The National Natural Science Foundation of China (No. 61300241) and the project consists of Zhuhai College of Jilin University teaching quality project provincial project "Baoli Garment Co. Ltd. of art department internship teaching base".

\section{REFERENCES}

[1] Yuan Ji,The future clothing and ecological and environmental problems of analysis. The costume designer,9(2001).

[2] Yimin Gu,"Green design" concept of the application in the clothing design and production. Journal of zhejiang textile vocational technology college, 2 (2009).p: 40.

[3] Lei Shen, Ying Xiong, Based on the ecological era of green garment design. Wool spinning technology,2 (2009).p: 60.

[4] Canyi Huang, Under the guidance of the sustainable development thought of the green clothing design. Journal of zhengzhou light industry social science edition, 4 (2010).p: 32-34

[5] Jingke Li,Zhen Xie, Outlook based on natural green clothing design. Ecological economy,10 (2009).p: 94. 